\title{
THE INFLUENCE OF THERMOSPHERIC WINDS ON THE AURORAL RED-LINE PROFILE OF ATOMIC OXYGEN
}

\author{
P. B. HAYS and S. K. ATREYA
}

High Altitude Engineering Laboratory, Department of Aerospace Engineering, Meteorology and Oceanography, The University of Michigan, Ann Arbor, Michigan 48105, U.S.A.

(Received in final form 10 May 1971)

\begin{abstract}
The effect of thermospheric winds on the emission profile of $\lambda 6300$ is discussed. It is shown that meridional winds play a significant role in determining the shape of this emission and the conventional diffusion of $\left.O{ }^{1} D\right)$ hypothesis, though important, is not adequate to explain the observed features completely.
\end{abstract}

Rees (1961) and Rees, Walker, and Dalgarno (1967) noted that the spatial distribution of the atomic oxygen red line emission in an aurora is strongly influenced by diffusion due to the long lifetime of $\mathrm{O}\left({ }^{1} D\right)$. We wish to point out that horizontal winds are of equal importance and may have an observable influence on the shape of $6300 \AA$ emission profile observed from the ground.

Recent doppler obscrvations (Hays and Roble, 1971) of mcridional winds in the thermosphere during magnetic storms indicate that speeds in excess of $300 \mathrm{~m} / \mathrm{sec}$ are not infrequent During the $110 \mathrm{sec}$ lifetime of an $O\left({ }^{1} \mathrm{D}\right)$ atom it can drift meridionally of the order of $30 \mathrm{~km}$. This is the same order as the diffusive drifts noted by Rees et al. (1967). Consequently, we have repeated the calculation of the red line plume for the aurora investigated by the above authors and introduced the influence of a lateral drift. Ignoring the vertical component of motion one solves the continuity equation:

$$
D \frac{\partial^{2} n}{\partial x^{2}}-v \frac{\partial n}{\partial x}-\left[A_{1_{D}}+n\left(\mathrm{~N}_{2}\right) \cdot K_{Q}\right] n=-P_{1_{D}}
$$

where $D$ is the diffusion coefficient for $\mathrm{O}\left({ }^{1} D\right)$ in $\mathrm{O}\left({ }^{3} P\right), n$ the $\mathrm{O}\left({ }^{1} D\right)$ density, $v$ the horizontal wind speed, $x$ the lateral coordinate, $A_{1_{D}}=1 / \tau_{D}$ the inverse of the ${ }^{1} D$ radiative lifetime, $K_{Q}$ the quenching coefficient for $\mathrm{O}\left({ }^{1} D\right)$ on $\mathrm{N}_{2}, n\left(\mathrm{~N}_{2}\right)$ the molecular nitrogen density and $P_{\mathbf{1}_{\boldsymbol{D}}}$ the $\mathrm{O}\left({ }^{1} D\right)$ production rate. This equation has the solution:

Case 1. $|x|>\Delta$ and $v \neq 0$

Case 2. $|x|<\Delta$ and $v \neq 0$

$$
n=\frac{Q}{D(\alpha-\beta)} \frac{e^{\beta x}}{\beta}\left(e^{-\beta \Delta}-e^{\beta \Delta}\right) .
$$

Where,

$$
n=\frac{Q}{D(\alpha-\beta)}\left[\frac{e^{\alpha x}}{\alpha}\left(e^{-\alpha x}-e^{-\alpha \Delta}\right)-\frac{e^{\beta x}}{\beta}\left(e^{-\beta x}-e^{\beta \Delta}\right)\right] .
$$

$$
\alpha=\frac{\frac{v}{D}+\sqrt{\left(\frac{v}{D}\right)^{2}+4\left[A_{1_{D}}+K_{Q} \cdot n\left(\mathrm{~N}_{2}\right)\right]}}{2}
$$

and

$$
\beta=\frac{\frac{v}{D}-\sqrt{\left(\frac{v}{D}\right)^{2}+4\left[A_{1_{D}}+K_{Q} \cdot n\left(\mathrm{~N}_{2}\right)\right]}}{2}
$$




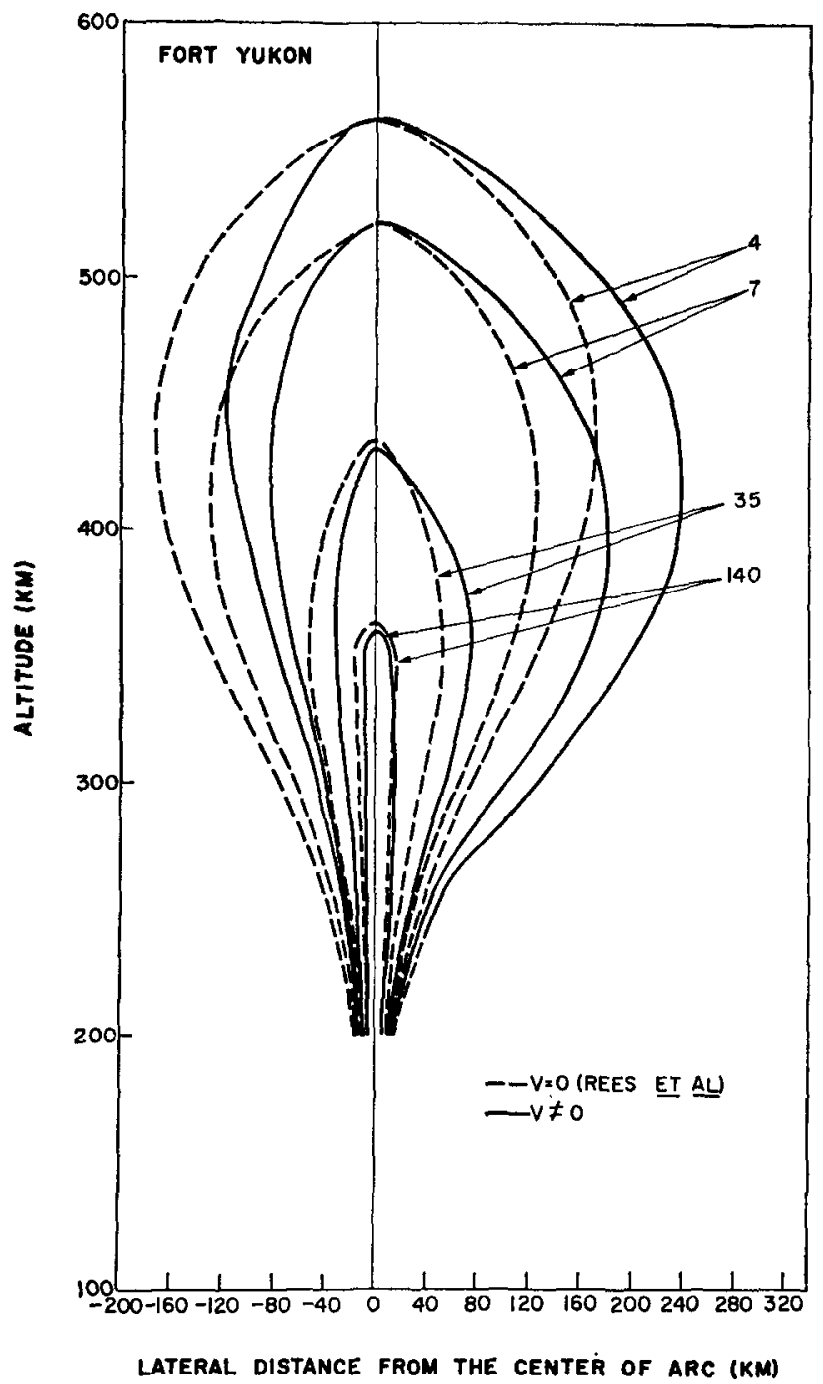

Fig. 1. The isophote Contours (Giving the volume emission Rate of $\lambda 6300$ IN PHOTONS $\mathrm{cm}^{-8} \mathrm{sec}^{-1}$ ) ILLUSTRATE THE SKEWNESS RESULTING PROM THE THERMOSPHERIC WINDS. 


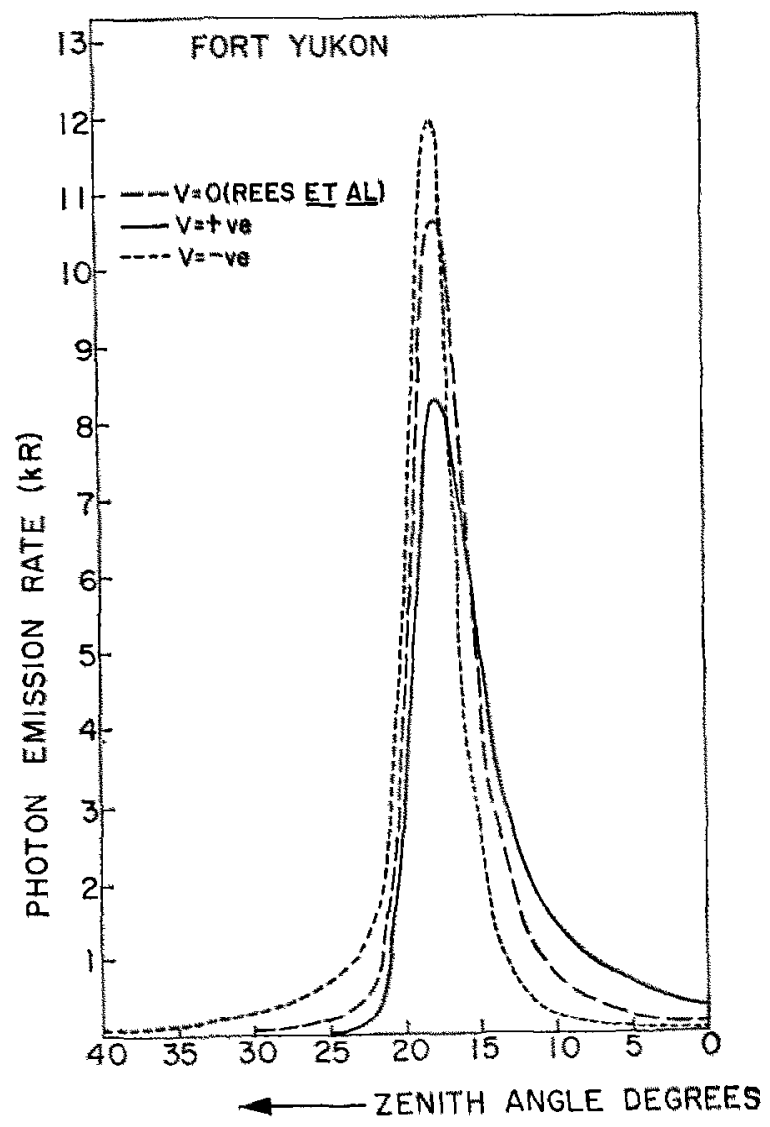

FIG. 2. THIR INTENSITY OF $\lambda 6300 \mathrm{iN}$ kR vs. LOCAL, ZENITH ANGLE FOR NON-ZERO THERMOSPHERIC WINDS AND THE CORRESPONDING CURYE FOR NO-WIND AT FORT YUKON.



FIG. 3. THE INTENSITY OF $\lambda 6300 \mathrm{IN} \mathrm{kR}$ VS. LOCAL ZENITH ANGTE FOR NON-ZERO THERMOSPHERIC WINDS AND THE CORRESPONDING CURVE FOR NO-WIND AT COLllege, AlasKa. 
where we have applied the boundary conditions that $n\left({ }^{1} D\right)=0$ as $|x| \rightarrow \infty$ and assumed a production rate $P_{1_{D}}=Q(z)$ for $x \leqslant \Delta$, where $\Delta$ is the semi-width of the arc $=3 \mathrm{~km}$. $P_{1_{b}}=0$ otherwise.

These results have been applied to the aurora discussed by Rees et al. (1967). In our calculations we have used a Bates model atmosphere as modified by Walker (1965) with $T(120 \mathrm{~km})=350^{\circ} \mathrm{K}$ and $T_{\infty}=1200^{\circ} \mathrm{K}$. The meridional wind field was calculated using the assumption that the latitudinal exospheric temperature gradient was $0 \cdot 1^{\circ} \mathrm{K} / \mathrm{km}$ to generate a pressure field. This allows one to evaluate the meridional wind profile shown in Table 1 directly from the neutral gas horizontal momentum equation (Geisler, 1966). The ionosphere used for ion drag was that given by Rees, Walker and Dalgarno (1967).

TABLE 1

\begin{tabular}{cccc}
\hline $\begin{array}{c}\text { Altitude } \\
Z(\mathrm{~km})\end{array}$ & $\begin{array}{c}\text { Wind velocity } \\
V(\mathrm{~m} / \mathrm{sec})\end{array}$ & $\begin{array}{c}\text { Altitude } \\
Z(\mathrm{~km})\end{array}$ & $\begin{array}{c}\text { Wind velocity } \\
V(\mathrm{~m} / \mathrm{sec})\end{array}$ \\
\hline 120 & $0 \cdot 0$ & 280 & 379 \\
140 & $15 \cdot 8$ & 300 & 398 \\
160 & $21 \cdot 2$ & 320 & 415 \\
180 & $56 \cdot 3$ & 340 & 431 \\
200 & 140 & 360 & 448 \\
220 & 226 & 380 & 466 \\
240 & 299 & 400 & 483 \\
260 & 350 & 420 & 499 \\
& & 440 & 513 \\
\hline
\end{tabular}

The Plume contour is illustrated on Fig. 1. Here the solid curve refers to the case where the meridional wind is non zero and the dotted contours are those obtained by Rees et al. (1967) for $v=0$. The skewness caused by the wind is obvious. This effect is further illustrated in Figs. 2 and 3 where the theoretical intensity curves discussed by Rees et al. (1967) at Fort Yukon and College, Alaska are presented. These stations were used by Belon, Romick and Rees (1966) in the original observations. We note that the agreement with the observations is not greatly better than that obtained previously, but the effect of winds is obviously significant. Romick (1964) has mentioned that the arc under investigation was not truly stable, it is suspected that the motion of the arc will contribute somewhat to the observed broadening. Consequently, one should analyze the more complex situation which includes the motion of the primary excitation source with time.

Acknowledgement-This research has been supported by a National Aeronautics and Space Administration Grant No. NGR-23-005-360.

\section{REFERENCES}

Belon, A. E., Romick, G. J. and Rees, M. H. (1966). Planet. Space Sci. 14, 597.

GeISLER, J. E. (1966). J. atmos. terr. Phys. 28, 703.

HAYs, P. B. and RnBt. F, R. G. (1971). J. geophys. Res. (In press).

ReES, M. H. (1961). Planet. Space Sci. 8, 59.

Rees, M. H., Walker, J. C. G. and Dalgarno, A. (1967). Planet. Space Sci. 15, 1097.

Romick, G. J. (1964). Ph D Thesis, University of Alaska.

WALKEK, J. C. G. (1965). J. Almos. Sti. 22, 462-463. 